\title{
Epidemiologic prediction of snake bites in tropical south Iran: Using seasonal time series methods
}

\author{
V. Ebrahimi ${ }^{\mathrm{a}}$, E. Hamdami ${ }^{\mathrm{b}, *}$, M.H. Khademian ${ }^{\mathrm{c}}$, M.D. Moemenbellah-Fard ${ }^{\mathrm{d}, *}$, B. Vazirianzadeh ${ }^{\mathrm{e}}$ \\ a Shiraz Nephro-Urology Research Center, Shiraz University of Medical Sciences, Shiraz, Iran \\ b Social Determinants in Health Promotion Research Center, Hormozgan Health Institute, Hormozgan University of Medical Sciences, Bandar Abbas, 79391-83417, Iran \\ ${ }^{\mathrm{c}}$ Department of Medical Surgical Nursing, School of Nursing and Midwifery, Shiraz University of Medical Sciences, Shiraz, Iran \\ ${ }^{\mathrm{d}}$ Research Center for Health Sciences, Institute of Health, Department of Medical Entomology and Vector Control, School of Health, Shiraz University of Medical Sciences, \\ Shiraz, 71645, Iran \\ ${ }^{\text {e }}$ Social Determinants of Health Research Center, Ahvaz Jundishapur University of Medical Sciences, Ahvaz, Iran
}

\section{A R T I C L E I N F O}

\section{Keywords:}

Snake bite

Reptile

Epidemiology

Viperidae

Correlation and time series models

Iran

\begin{abstract}
A B S T R A C T
Background: Snakebite envenomation is a vital status necessitating immediate treatment following case detection. Many cases of snakebites are recorded every year due to the suitable climatic conditions for the existence and survival of snakes in south Iran.

Methods: In the present retrospective cross-sectional study, 195 snake (Reptilia: Squamata: Viperidae; Echis carinatus sochureki) bite cases referred to 10 rural health centers, two health care stations and the Haji-Abad Central Hospital of Hormozgan University of Medical Sciences (HUMS) were surveyed during 2012-2016. Seasonal time series models were applied to fit a linear model to describe and predict the monthly trend of snakebite cases.

Results: Among these patients, males $(70 \%, 136)$ from rural areas $(79.5 \%, 155)$ were mostly recorded. The mean ( \pm SD) age of victims was 33 ( \pm 17.0 ) years old and the most common age group was 20-29 years (32\%). Most snakebites took place outdoors (80\%), on hands and legs (97\%), and among unemployed people and farmers (61.0\%). Snakebites often happened between midnight and 6 am (32\%); also 51\% of them occurred during summer. Most (70\%) patients had pain at the bite sites. The location of being bitten (indoors or outdoors) had a significant difference with patient's sex $\left(\chi^{2}=7.764, P=0.021\right)$.

Conclusions: Time series analysis proposed a mixed seasonal autoregressive moving average, ARMA $(1,0) \times(1,1)_{12}$ as the best process for the monthly trend of snakebite and to predict the incidence of snakebites. Local residents should be more cautious on snakebites during warm seasons.
\end{abstract}

\section{Background}

Snakebite envenomation is an urgent event requiring instantaneous treatment following detection. Venomous snakes are mysterious reptiles dispersed all over the world especially in tropical and subtropical countries except the polar and high mountain areas. ${ }^{1}$ They are coldblooded carnivores and are entirely active at temperatures from 22 to $25^{\circ} \mathrm{C} .{ }^{2}$

About 600 of the 3000 or so species of snakes worldwide are venomous and potentially dangerous to humans. ${ }^{3}$ Acute medical emergencies can be engendered after being bitten by venomous snakes including irreversible renal failure, bleeding disturbance, severe paralysis that may include dyspnoea leading possibly to asphyxia, and severe local tissue necrosis that may require limb amputation. ${ }^{4}$ Snakebite must therefore be considered very carefully as a worldwide fatal problem regarding curing, otherwise, snakebites can lead to destructive consequences in envenomed patient. ${ }^{1,5}$

There are various estimates on the total number of snakebites and the death toll from the venomous snakes worldwide. ${ }^{1,3,4,6}$ Generally, the number of snakebites, envenomation and its associated deaths are hard to reckon since most estimates are based on inadequate datasets or annual hospital returns. It also appears that most victims succumb themselves to self-cure at home using traditional treatment instead of receiving hospital treatment ${ }^{7}$ and some of them might die at home without their records being saved. ${ }^{8}$

Nevertheless, the best prediction on the worldwide number of snakebites indicated that the total number of snakebites ranges from 1.2 to 5.5 M cases annually, of which envenomation ranged from 421,000 to

\footnotetext{
* Corresponding authors.

E-mail addresses: biostat.ebrahimiv@gmail.com (V. Ebrahimi), hamdamie@gmail.com (E. Hamdami), khademianm@sums.ac.ir (M.H. Khademian), momenbf@sums.ac.ir (M.D. Moemenbellah-Fard), babakvazir@yahoo.co.uk (B. Vazirianzadeh).
} 
$1,841,000$ per year and the most venomous snakebites took place in south Asia followed by south-east Asia and east Sub-Saharan Africa. The number of deaths due to envenomation were variable between 20,000 and 94,000 annually. ${ }^{3,}$,

From all species of snakes in the world, 83 species are recognized in Iran including 45, 11, and 27 aglyphous (no groove), opisthoglyphous (rearward grooved fangs), and venomous species, respectively. ${ }^{10},{ }^{11}$ The poisonous snakebite is an important public health issue, particularly in rural areas. Various species of poisonous snakes exist due to the special geographic and climate conditions. The four common families of snakes in Iran are Colubridae, Elapidae, Viperidae, and Hydrophidae, which determine the type of snake venom.

In Iran, the most dangerous snakes are of the Viperidae family including the Echis carinatus sochureki which is found in the northeastern, south, southeastern and southwestern parts and Vipera lebetina obtuse which is found in the north and northeastern parts of the country. ${ }^{11}$

At least 7000 cases of snakebites are annually reported with about 3-9 deaths in Iran. ${ }^{1}$ A few provinces such as Khorasan, Sistan-Baluchistan, Khuzestan, and Hormozgan have the highest numbers of snakebites, respectively. Hormozgan with incidences of 31 per 100,000 individuals is in the 4th place for snakebite events. There are 9 different species of terrestrial snakes in Haji-Abad, Hormozgan province, Iran (2 in Viperidae and 7 in Colubridae families). ${ }^{2}{ }^{11}$ Table 1 shows a list of some of the most common terrestrial snakes in this province. In order to forecast the future trend of snakebites and adopt the indispensable measures to ameliorate this problem, statistical analyses (such as time series processes) could be implemented to provide a foundation to logical decision making. To analyze time series data such as that presented below obtained from the observation of an event over time, analyses of time series could be useful.

The main aim of the present study was to describe and predict the epidemiological features of snakebite cases using mixed seasonal autoregressive moving average (ARMA) method. Correlation models and descriptive statistics were implemented to describe the relationship between envenoming cases with climate parameters. To the best of our knowledge, this is the first study in Iran using mixed seasonal ARMA method to identify the factors that have an important impact on activity of snakes and also to predict future number of needed polyvalent antivenoms.

\section{Materials and method}

\subsection{Study area}

The study area is the city of Haji-Abad in the north of Hormozgan province in Iran (Fig. 1), which is located at $28^{\circ} 18^{\prime} 33^{\prime \prime} \mathrm{N}, 55^{\circ} 54^{\prime} 6^{\prime \prime} \mathrm{E}$ of the equator and according to the 2011 census, conducted by the statistical center of Iran (SCI), its population was about 66,000 people in 11,000 square kilometers of area. It has a tropical climate with minimum temperature of about $-3.6{ }^{\circ} \mathrm{C}$ during winter (December-January) and $46.6{ }^{\circ} \mathrm{C}$ during summer (July-June). Moreover, the annual rainfall is about $160 \mathrm{~mm} .^{12,13}$

\subsection{Data acquisition}

In this retrospective cross-sectional survey, medical documents of all snakebite victims $(\mathrm{n}=195)$, referred to 10 rural health centers, two healthcare stations and the Haji-Abad Central Hospital affiliated to Hormozgan University of Medical Sciences (HUMS) between June 2012-August 2016, were analyzed. The patients' data were collated in a standard national form which included major clinical symptoms but excluded treatment details. Extracted data from the available records included demographic and epidemiologic features of snakebites along with climate data obtained from the Bureau of Meteorology Station of Haji-Abad. The deficits in data were the only exclusion criteria in this study.

Some important demographic and epidemiologic variables were analyzed concerning snakebite, including age of the victim at the time of event, sex, victim's job, region (rural/urban), date of event, location (indoor/outdoor), site of bite on the victim's body, time of bite, the elapsed time from the bite to the treatment, and history of bite.

\subsection{Statistical analysis}

Chi-square test and descriptive statistics were used to present epidemiologic findings. Various time series processes were implemented especially mixed seasonal ARMA, and ARMA $(p, q) \times(P, Q)_{h}$, models to describe the behavior of data over time. Autocorrelation (ACF) and partial autocorrelation functions (PACF) are two valuable and helpful tools to determine primary $\mathrm{q}$ (or $\mathrm{Q}$ ) and $\mathrm{p}$ (or P), respectively. ${ }^{14},{ }^{15}$

Root mean square error (RMSE) criterion obtained from the residuals of the model fitting, and also applying the modified Box-Pierce test and other diagnostic measures was computed to select the optimal model. ${ }^{14-16}$ Among the candidate models, the one which consistently had the smallest value of RMSE with fewer parameters satisfying the best diagnostic measures was chosen as the optimal fitting model. ${ }^{14-17}$

The Pearson correlation statistics, $r$, was applied to determine any significant relation between the climate factors and the number of monthly snakebite data. ${ }^{18},{ }^{19}$

Statistical analyses were done using SPSS software, version 16.0, and Minitab software, Version 17.1.0. A $P$-value $<0.05$ was considered as significant.

\section{Results}

\subsection{Demographic and epidemiologic data}

Among all 195 snakebite cases, most (136, 70\%) victims were males. In addition, most (155, 79.5\% including $108,55 \%$ male) patients were from rural areas and a quintile $(40,21 \%)$ from urban areas. The mean $( \pm S D)$ age of the snakebite victims was $33( \pm 17.0)$ years (range: 2-81 yr.) and also the most common age group was 20-29 yr. (62, 32\%). Most of the victims $(119,61 \%)$ were unemployed people and farmers followed by housewives (25.1\%) (Table 2).

Most $(155,80 \%)$ snakebites occurred outdoors and between

Table 1

Frequency distribution of common terrestrial snakes in Hormozgan Province, Iran.

\begin{tabular}{|c|c|c|c|}
\hline World distribution & Species & Group & Family \\
\hline Eastern North of Africa, South and South West of Asia, Saudi Arabia, Cameron, Iran, Oman, Pakistan & Echis carinatus sochureki & venomous & Viperidae \\
\hline Afghanistan, Iran, Iraq, Oman, Pakistan & Pseudocerastes persicus persicus & & \\
\hline Iran, India, Pakistan, Saudi Arabia, Sri Lanka, Tajikistan & Boiga trigonatum melanocephala & semi-toxic & Colubridae \\
\hline Egypt, Iran, North of Africa, Saudi Arabia, Turkey & Malpolon monspessulanus insignitus & & \\
\hline Egypt, Iran, Iraq, Saudi Arabia, Sudan, Syria & Malpolon moilensis & & \\
\hline Afghanistan, Egypt, Iran, Iraq, Pakistan, Saudi Arabia, Syria, Somali, Turkmenistan & Coluber rhodorachis & non-toxic & \\
\hline Iran, Iraq, Kuwait, Oman, Saudi Arabia & Lytorhynchus diadema gaddi & & \\
\hline Afghanistan, Egypt, Iran, Iraq, Pakistan, Saudi Arabia, Sudan & Spalerosophis diadema cliffordii & & \\
\hline Afghanistan, India, Iran, Kazakhstan Pakistan, Turkmenistan & Spalerosophis diadema schirasianus & & \\
\hline
\end{tabular}




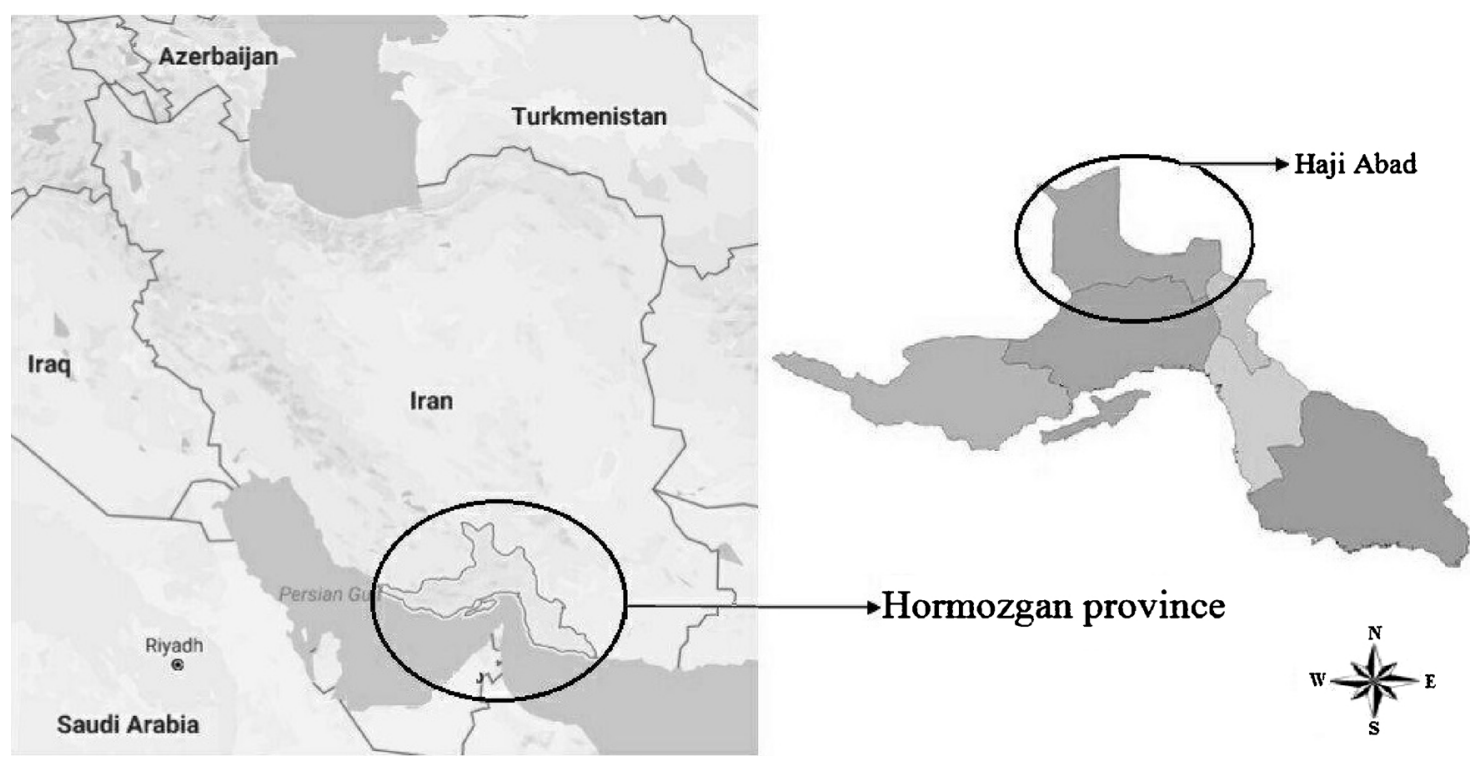

Fig. 1. Location of the study area in Hormozgan province and Iran.

Table 2

Patient' demographic and epidemiologic features $(n=195)$.

\begin{tabular}{|c|c|c|c|c|}
\hline Variable & Sub group & $\begin{array}{l}\text { Male (136, } \\
69.7 \%) \\
\text { Frequency } \\
(\%)\end{array}$ & $\begin{array}{l}\text { Female (59, } \\
30.3 \%) \\
\text { Frequency } \\
(\%)\end{array}$ & Total (\%) \\
\hline \multicolumn{5}{|l|}{ Demographics } \\
\hline \multirow{2}{*}{$\begin{array}{l}\text { Region of } \\
\text { occurrence }\end{array}$} & Rural & $108(55.4)$ & $47(24.1)$ & 155(79.5) \\
\hline & Urban & $28(14.4)$ & $12(6.2)$ & $40(20.6)$ \\
\hline \multirow{6}{*}{$\begin{array}{l}\text { Victim's age } \\
\text { (years) }\end{array}$} & $1-9$ & $6(3.1)$ & $4(2.1)$ & $10(5.2)$ \\
\hline & $10-19$ & $22(11.3)$ & $5(2.6)$ & $27(13.9)$ \\
\hline & $20-29$ & $47(24.1)$ & $15(7.7)$ & $62(31.8)$ \\
\hline & $30-39$ & $28(14.4)$ & $10(5.1)$ & $38(19.5)$ \\
\hline & $40-49$ & $12(6.2)$ & $6(3.1)$ & $18(9.3)$ \\
\hline & $>50$ & $21(10.6)$ & $19(9.7)$ & $40(20.3)$ \\
\hline \multirow[t]{4}{*}{ Victim's job } & Housewife & $0(0)$ & $49(25.1)$ & $49(25.1)$ \\
\hline & Student & $17(8.7)$ & $4(2.1)$ & $21(10.8)$ \\
\hline & Employee & $6(3.1)$ & $0(0)$ & $6(3.1)$ \\
\hline & $\begin{array}{l}\text { Unemployed } \\
\text { and farmers }\end{array}$ & $113(57.9)$ & $6(3.1)$ & $119(61.0)$ \\
\hline \multicolumn{5}{|l|}{ Epidemiologic } \\
\hline \multirow[t]{3}{*}{ Site of bite } & Hand & $66(33.8)$ & $26(13.4)$ & $92(47.2)$ \\
\hline & Leg & $68(34.8)$ & $30(15.4)$ & $98(50.2)$ \\
\hline & Trunk & $2(1.0)$ & $3(1.6)$ & $5(2.6)$ \\
\hline \multirow[t]{3}{*}{ History of bite } & Snake bite & $18(9.2)$ & $9(4.6)$ & $27(13.8)$ \\
\hline & Scorpion sting & $14(7.2)$ & $9(4.6)$ & $23(11.8)$ \\
\hline & None & $104(53.3)$ & $41(21.1)$ & $145(74.4)$ \\
\hline \multirow{3}{*}{$\begin{array}{l}\text { Time (h) from the } \\
\text { bite to the } \\
\text { treatment }\end{array}$} & $<3$ & $102(52.3)$ & $43(22.1)$ & $145(74.4)$ \\
\hline & $3-6$ & $17(8.7)$ & $9(4.6)$ & $26(13.3)$ \\
\hline & $>6$ & $17(8.7)$ & $7(3.6)$ & $24(12.3)$ \\
\hline \multirow[t]{2}{*}{ Location of bite } & Indoor & $22(11.3)$ & $18(9.2)$ & $40(20.5)$ \\
\hline & Outdoor & $114(58.5)$ & $41(21.0)$ & 155(79.5) \\
\hline \multirow[t]{4}{*}{ Time of bite (h) } & $0-6$ & $48(24.6)$ & $14(7.2)$ & $62(31.8)$ \\
\hline & $6-12$ & $33(16.9)$ & $17(8.7)$ & $50(25.6)$ \\
\hline & $12-18$ & $27(13.8)$ & $15(7.7)$ & $42(21.5)$ \\
\hline & $18-24$ & $28(14.4)$ & $13(6.7)$ & $41(21.1)$ \\
\hline
\end{tabular}

midnight and 6 a.m. (62, 32\%). About half of the bites were on the legs (98, 50\%), followed by hands (92, 47\%) and trunks (5, 3\%). Out of 195 reported cases, only 50 patients had previously been bitten by snakes and scorpions (27 and 23 patients, respectively). These findings showed that most patients with snakebites $(145,74 \%)$ referred to the clinic less than $3 \mathrm{~h}$ after the bites (Table 2). Location of being bitten (outdoor/ indoor) was significantly different between male and female $\left(\chi^{2}=5.184, P=0.023\right)$ and in both places women were less bitten by snakes than men.
The highest and the lowest numbers of recorded snakebites happened in 2014 and 2016 with 50 and 28 cases, respectively. Most snakebites $(100,51 \%)$ occurred during summer while the least $(15,8 \%)$ took place in winter. The lowest rate of snakebite cases $(2, \sim 1 \%)$ was reported in December, while the peak (36, 19\%) occurred in June and July during the summer (Figs. 2 and 3 ).

\subsection{Clinical symptoms and signs}

Considering the signs and symptoms, redness around the bite area was observed only in $63(32.3 \%)$ patients. Of all victims, $136(69.7 \%)$ had pains at the bite site, but only $13(6.7 \%)$ and $2(1 \%)$ patients had severe muscle pain and numbness in the limbs or body, respectively (Table 3).

Of the 195 patients, 21 (11\%) reported systemic symptoms due to snakebites, such that the signs of central, sympathetic, and parasympathetic nervous systems were observed in $9(5 \%), 8$ (4\%), and 4 (2\%) patients, respectively.

\subsection{Time series model to determine the monthly trend of snakebites}

Using the time series plot in Fig. 4, snakebites did not follow any systematic pattern over time and had random behavior. ACF and PACF functions were thus plotted for snakebites in Fig. 5. Since both the ACF and PACF plots were significant only in the first lag, ARMA $(1,1)$ is fitted as a suggested model. But assessing associated residual plot (graph not shown) revealed that there was a seasonal trend in the data. Although ACF and PACF for residual suggest an $\mathrm{AR}^{1}$ model for seasonal trend, but in the ARMA $(1,1) \times(1,1)_{12}$ model, AR ${ }^{1}$ and SAR ${ }^{12}$ were not significant $(P=0.276$ and 0.831 , respectively). Based on the corresponding RMSE value, the ARMA $(1,0) \times(1,1)_{12}$ had the best fit for the available data and was thus considered the optimal model (Table 4). The modified Box-Pierce test for this optimal model shows that the model is detected statistically well and no statistically significant difference exists between the observed and fitted values by model.

As another diagnostic check, the 4-in-1 residual plots are depicted in Fig. 6. They indicate that the fit is indeed acceptable and confirm goodness of the suggested model. The adequacy of the proposed model is also approved using Fig. 7. This Figure shows that partial autocorrelations and autocorrelations are near zero which reveals that the residuals were not significant at all lags. Fig. 8 also displays the plot of actual data and the fitted values together over the period of study. It 


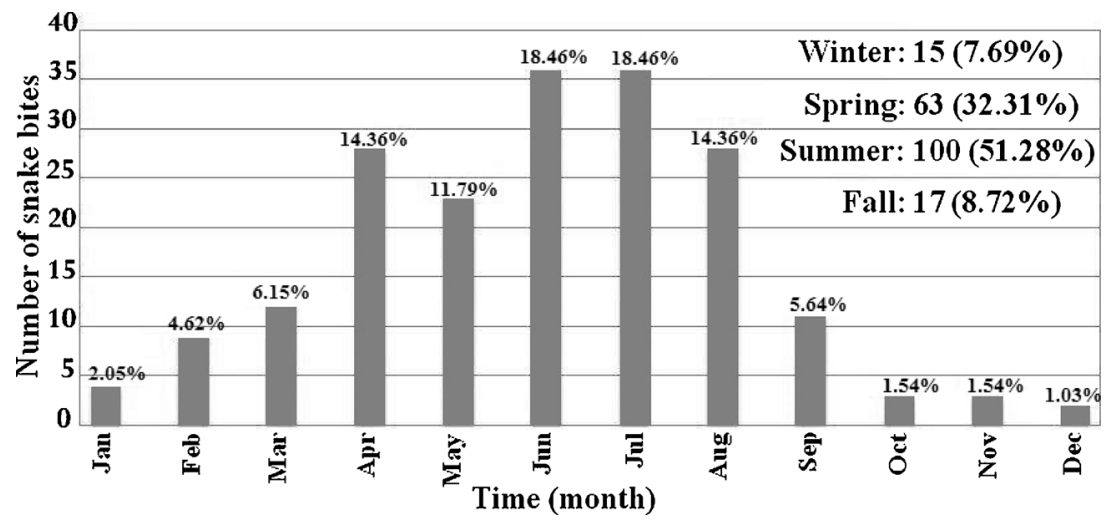

Fig. 2. Distribution of snake bite cases based on different months and seasons, 2012-2016.

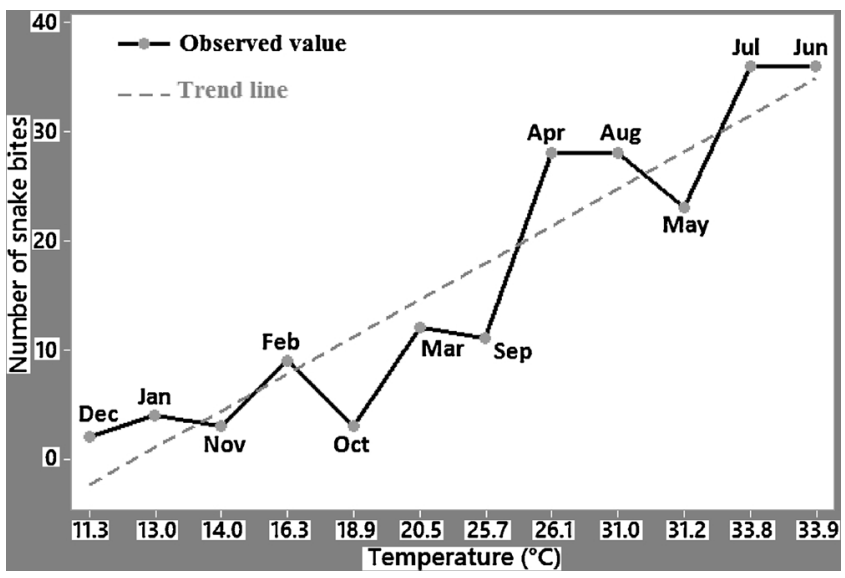

Fig. 3. Distribution of average of snakebite cases with respect to the average temperatures in various months of the years 2012-2016.

Table 3

Descriptive of patients' clinical signs and symptoms $(n=195)$.

\begin{tabular}{|c|c|c|c|c|c|}
\hline \multicolumn{3}{|c|}{ Signs and Symptoms } & $\begin{array}{l}\text { Male (136, } \\
69.7 \%) \\
\text { Frequency } \\
(\%)\end{array}$ & $\begin{array}{l}\text { Female (59, } \\
30.3 \%) \\
\text { Frequency } \\
(\%)\end{array}$ & Total (\%) \\
\hline \multirow{8}{*}{$\begin{array}{l}\text { Local } \\
\text { symptoms }\end{array}$} & \multirow{4}{*}{$\begin{array}{l}\text { Redness around } \\
\text { the bite site } \\
\text { Localized pain }\end{array}$} & Yes & $40(20.5)$ & $23(11.8)$ & $63(32.3)$ \\
\hline & & No & $96(49.2)$ & $36(18.5)$ & $132(67.7)$ \\
\hline & & Yes & $95(48.7)$ & $41(21.0)$ & $136(69.7)$ \\
\hline & & No & $41(21.0)$ & $18(9.3)$ & $59(30.3)$ \\
\hline & \multirow{2}{*}{$\begin{array}{l}\text { Numbness in limb } \\
\text { or body }\end{array}$} & Yes & $10(5.1)$ & $3(1.6)$ & $13(6.7)$ \\
\hline & & No & $126(64.6)$ & $56(28.7)$ & $182(93.3)$ \\
\hline & \multirow{2}{*}{$\begin{array}{l}\text { Severe muscle } \\
\text { pain }\end{array}$} & Yes & $1(0.5)$ & $1(0.5)$ & $2(1.0)$ \\
\hline & & No & $135(69.3)$ & $58(29.7)$ & 193(99.0) \\
\hline \multirow{6}{*}{$\begin{array}{l}\text { Systemic } \\
\text { symptoms }\end{array}$} & \multirow{2}{*}{$\begin{array}{l}\text { Signs of } \\
\text { sympathetic } \\
\text { nervous system }\end{array}$} & Yes & $6(3.1)$ & $2(1.0)$ & $8(4.1)$ \\
\hline & & No & $130(66.7)$ & $57(29.2)$ & $187(95.9)$ \\
\hline & \multirow{2}{*}{$\begin{array}{l}\text { Signs of } \\
\text { parasympathetic } \\
\text { nervous system }\end{array}$} & Yes & $3(1.6)$ & $1(0.5)$ & $4(2.1)$ \\
\hline & & No & $133(68.2)$ & $58(29.7)$ & 191(97.9) \\
\hline & \multirow{2}{*}{$\begin{array}{l}\text { Signs of central } \\
\text { nervous system }\end{array}$} & Yes & $8(4.1)$ & $1(0.5)$ & $9(4.6)$ \\
\hline & & No & $128(65.7)$ & $58(29.7)$ & $186(95.4)$ \\
\hline
\end{tabular}

seems that the fitted values smooth out the highs and lows in the data, indicating that the fitted values are a suitable and proper estimator of observed values.

\subsection{Correlations between climate factors and snakebite cases}

In Table 5, the correlation coefficients $(r)$ between the monthly

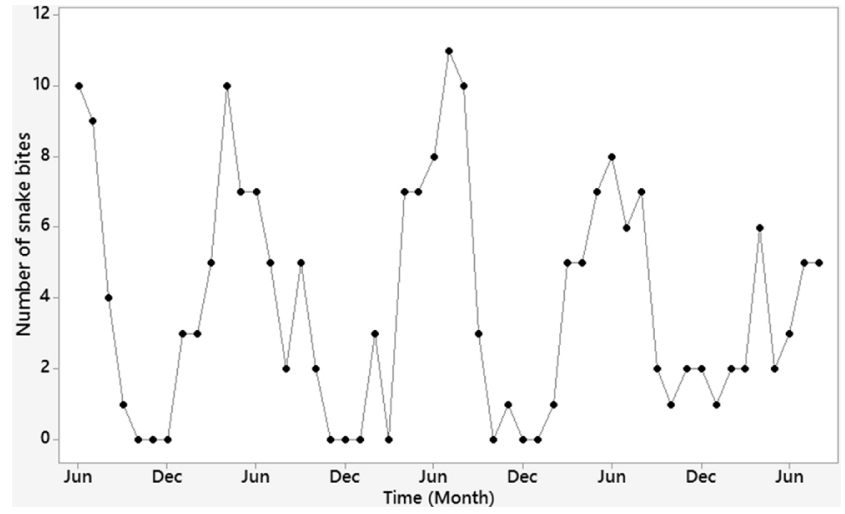

Fig. 4. Time series plot of snakebite cases from June 2012 to August 2016.

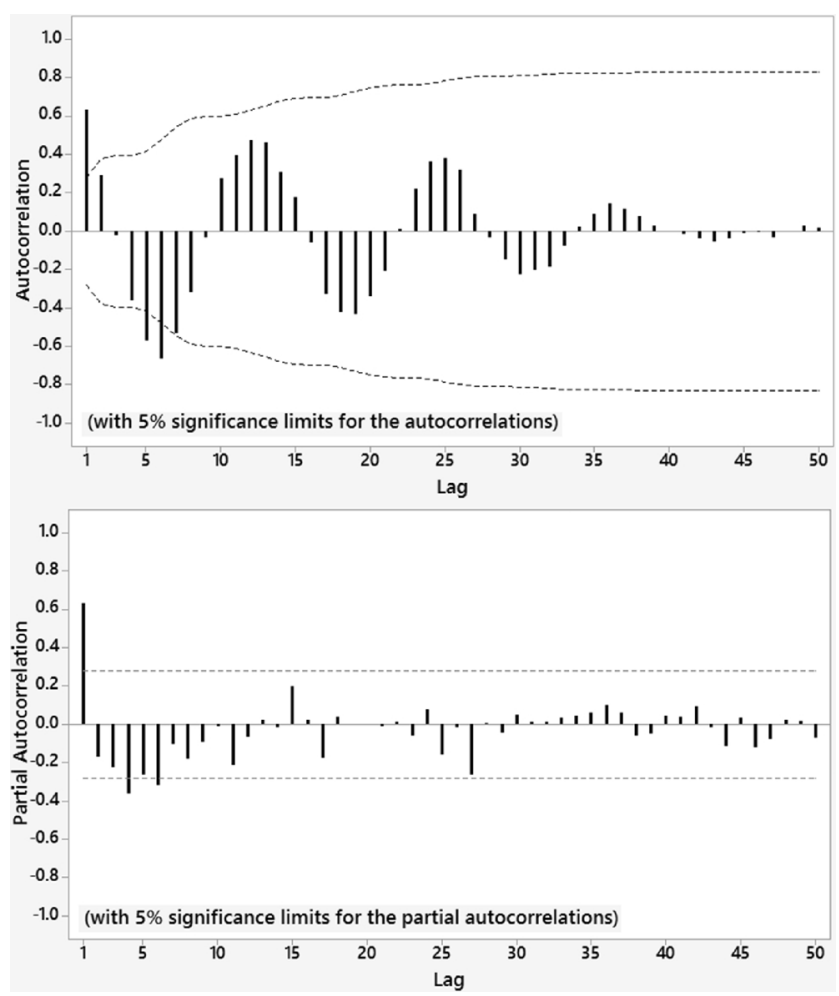

Fig. 5. Plot of autocorrelation (ACF) and partial autocorrelation (PACF) functions for snakebite cases. 
Table 4

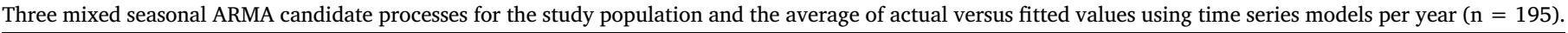

\begin{tabular}{|c|c|c|c|c|}
\hline \multicolumn{5}{|l|}{ Model } \\
\hline $\operatorname{ARMA}(1,1) \times(1,1)_{12}$ & Coef & S.E. & $P$-value & RMSE \\
\hline AR (1) & 0.362 & 0.329 & 0.276 & 1.970 \\
\hline MA (1) & -0.074 & 0.347 & $<0.001^{*}$ & \\
\hline SAR(12) & 0.998 & 0.034 & 0.831 & \\
\hline SMA(12) & 0.812 & 0.167 & $<0.001^{*}$ & \\
\hline Constant & 0.009 & 0.082 & 0.915 & \\
\hline \multirow[t]{4}{*}{ Modified Box-Pierce test } & Lag & Chi-square & df & $P$-value \\
\hline & 12 & 10.3 & 7 & 0.170 \\
\hline & 24 & 28.9 & 19 & 0.068 \\
\hline & 36 & 38.6 & 31 & 0.164 \\
\hline $\operatorname{ARMA}(1,0) \times(1,0)_{12}$ & Coef & S.E. & $P$-value & RMSE \\
\hline AR (1) & 0.532 & 0.126 & $<0.001^{*}$ & 2.307 \\
\hline SAR(1) & 0.420 & 0.141 & $0.004^{*}$ & \\
\hline Constant & 1.053 & 0.325 & $0.002^{*}$ & \\
\hline \multirow[t]{4}{*}{ Modified Box-Pierce test } & Lag & Chi-Square & df & $P$-value \\
\hline & 12 & 16.4 & 9 & 0.058 \\
\hline & 24 & 33.0 & 21 & $0.047^{*}$ \\
\hline & 36 & 43.9 & 33 & 0.097 \\
\hline $\operatorname{ARMA}(1,0) \times(1,1)_{12}$ & Coef & S.E. & $P$-value & \\
\hline $\operatorname{AR}(1)$ & 0.425 & 0.134 & $0.003^{*}$ & 1.946 \\
\hline $\operatorname{ASR}(12)$ & 0.998 & 0.033 & $<0.001^{*}$ & \\
\hline SMA(12) & 0.814 & 0.164 & $<0.001^{*}$ & \\
\hline Constant & 0.008 & 0.070 & 0.913 & \\
\hline \multirow[t]{4}{*}{ Modified Box-Pierce test } & Lag & Chi-Square & df & $P$-value \\
\hline & 12 & 10.4 & 8 & 0.238 \\
\hline & 24 & 28.7 & 20 & 0.100 \\
\hline & 36 & 38.6 & 32 & 0.196 \\
\hline
\end{tabular}

Average of Actual versus Fitted values of snakebite via $\operatorname{ARMA}(1,0) \times(1,1)_{12}$ per year

\begin{tabular}{|c|c|c|c|c|c|c|c|c|c|c|c|c|c|}
\hline Month & Jan & Feb & Mar & Apr & May & Jun & Jul & Aug & Sep & Oct & Nov & Dec & Total \\
\hline Actual & 0.9 & 2.3 & 3.0 & 6.0 & 5.8 & 7.2 & 7.2 & $5.6^{\circ}$ & 3.2 & 0.8 & 0.8 & 0.5 & 43.1 \\
\hline Fitted & 1.1 & 2.3 & 2.9 & 7.3 & 5.4 & 7.1 & 7.4 & 5.8 & 2.6 & 1.0 & 1.0 & 0.8 & 44.6 \\
\hline
\end{tabular}

* $P$-value $<0.05$ is significant. Abbreviations: Coef, coefficient; df, degree of freedom; RMSE, root mean square error; ARMA $(\mathbf{p}, \mathbf{q}) \times(\mathbf{P}, \mathbf{Q})_{12}$, mixed seasonal ARMA at lag 12; S.E., standard error.
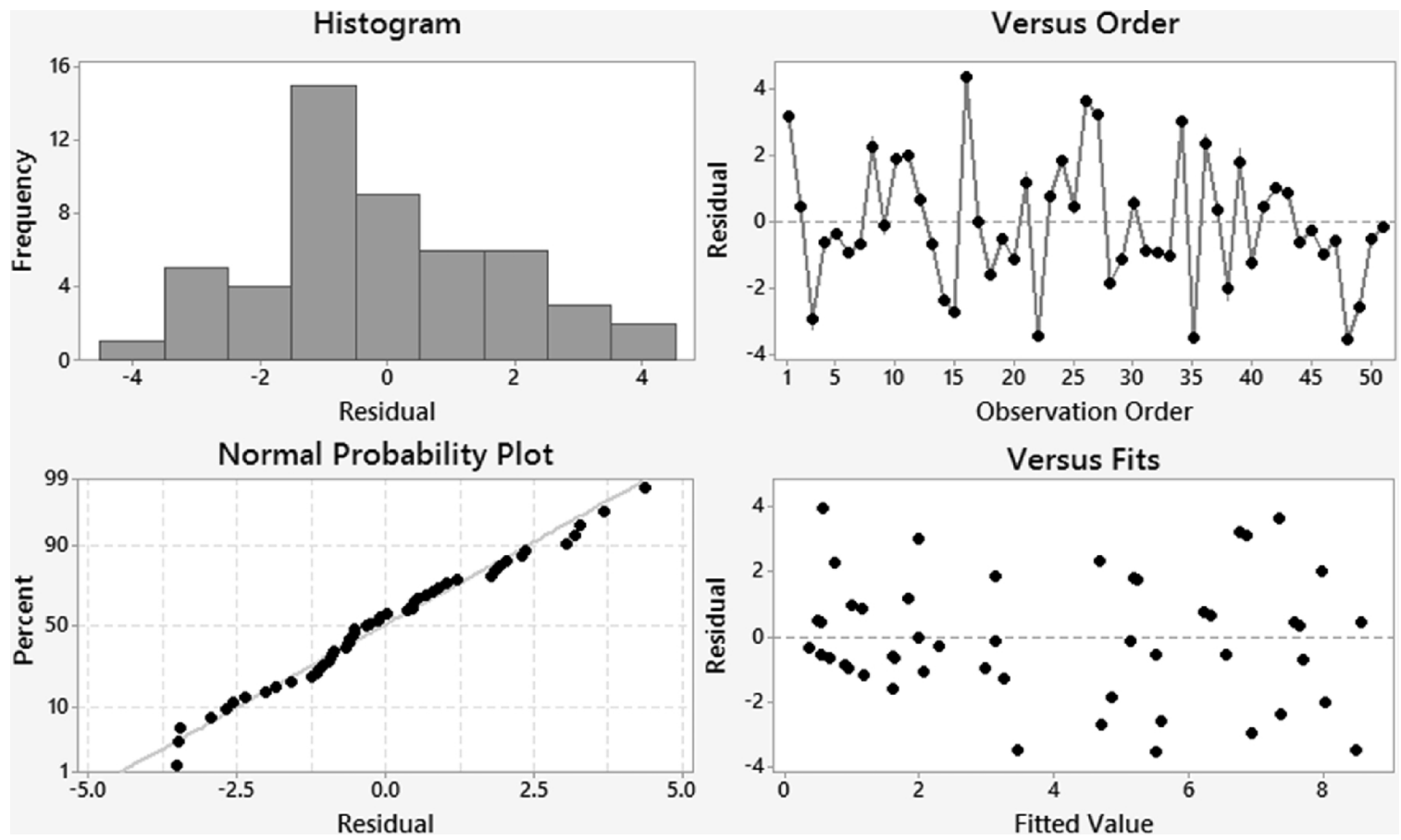

Fig. 6. Plot of residual versus ordered times, histogram of residuals, normal probability plot, and plot of residual versus fitted values for snakebite cases in fitting mixed seasonal ARMA model, ARMA $(1,0) \times(1,1)$. 

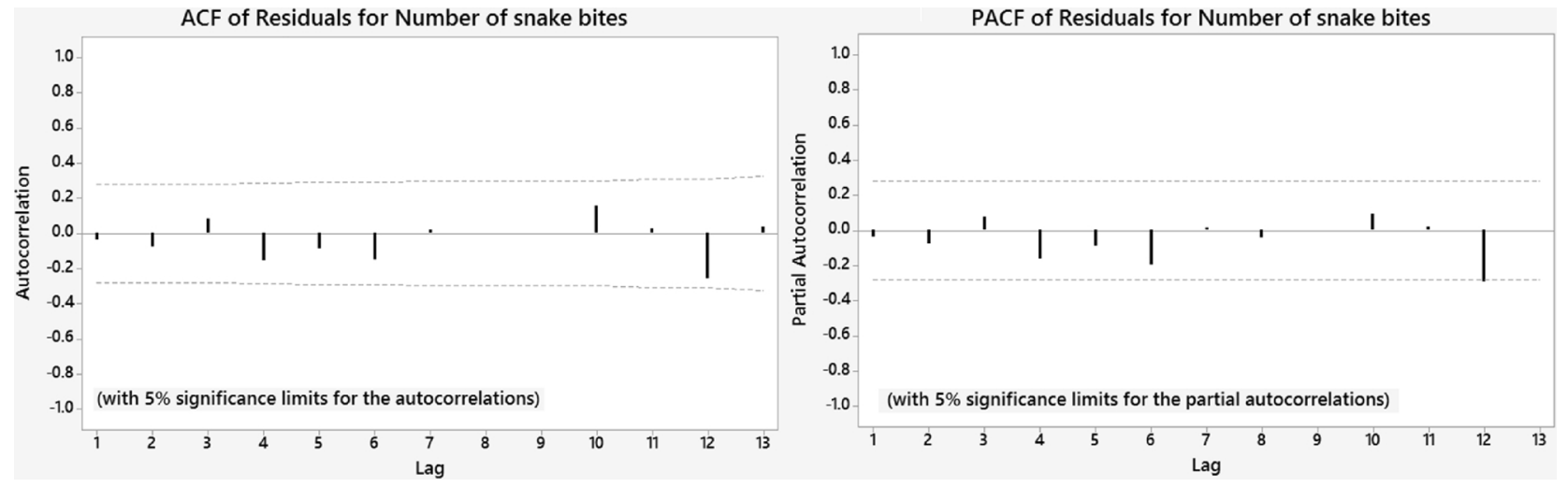

Fig. 7. Plot of autocorrelation (ACF) and partial autocorrelation (PACF) of residuals for snakebite data set.

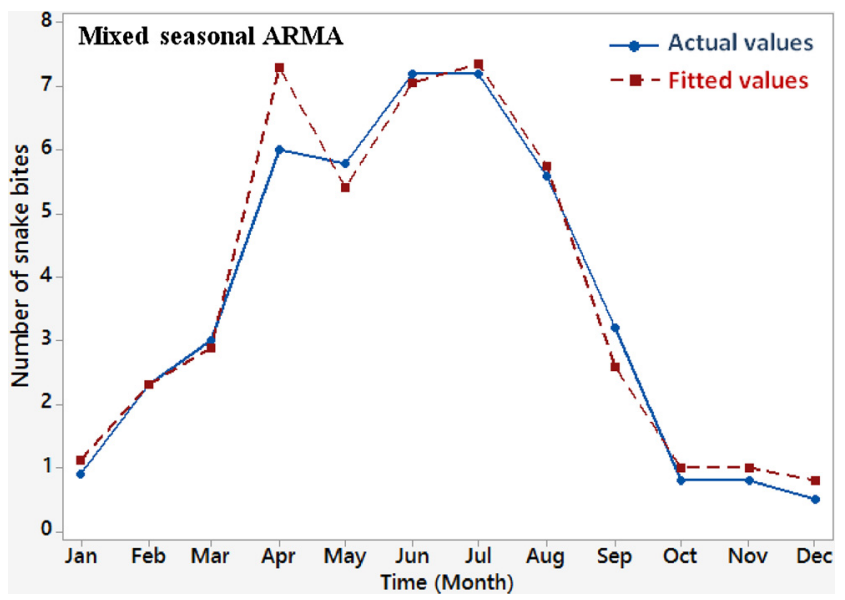

Fig. 8. Plot of average of the actual observations and fitted values for snakebite cases per year via ARMA $(1,0) \times(1,1)_{12}$ model.

Table 5

Correlation coefficients ( $r$ ) of snakebite with the averages of monthly climate factors.

\begin{tabular}{lllllll}
\hline Factors & Minimum & Maximum & Mean & S.D. & r & $P$-value \\
\hline R (mm) & 0.0 & 115.4 & 15.0 & 23.5 & -0.307 & $0.027^{*}$ \\
SH (h) & 214.0 & 384.0 & 296.0 & 41.0 & 0.584 & $<0.001^{*}$ \\
T $\left({ }^{\circ} \mathbf{C}\right)$ & 9.6 & 34.4 & 24.0 & 8.0 & 0.730 & $<0.001^{*}$ \\
WV (m/s) & 8.0 & 28.0 & 17.0 & 4.5 & 0.114 & 0.420 \\
RH (\%) & 19.0 & 58.0 & 44.0 & 9.5 & -0.618 & $<0.001^{*}$
\end{tabular}

* $P$-value $<0.05$ is significant. Abbreviations: $\mathrm{R}$, rainfall; $\mathrm{RH}$, relative humidity; S.D., standard deviation; SH, sunlight hours; T, temperature; WV, wind velocity.

averages of all climate parameters and snakebite cases were seen significant $(P<0.05)$, except for wind velocity (WV) $(P=0.420)$. In this study, significant positive correlations were observed between numbers of snakebites and sunlight hours (SH), $(\mathrm{r}=0.584, P<0.001)$, and temperature $(\mathrm{T}),(\mathrm{r}=0.730, P<0.001)$. An inverse correlations was found between the incidence of snakebites and rainfall $(\mathrm{R}),(\mathrm{r}=-0.307$, $P=0.027)$, and relative humidity (RH), $(\mathrm{r}=-0.618, P<0.001)$.

\section{Discussion}

In some parts of the world, like Iran, envenomation by snakebites is a major neglected public health issue,$^{20}$ despite the potential simultaneous risks imposed by many infectious ${ }^{21-23}$ and non-infectious diseases. ${ }^{24}$ The collected data displayed that snakebite cases had a correlated structure during the study time period of 51 months; thus, the use of time series model is a suitable approach to characterize the monthly trend of data.

Among several candidate time series models, ARMA $(1,0) \times(1,1)_{12}$ had the least amount of RMSE values, and it was selected as an optimal model for $>4$ years of snakebites data. In fact, the proposed model generates the best estimates of the future cases of snakebites, and it can help public health authorities design necessary measures.

Recently, several studies have investigated the effects of different and important factors on the incidence of snakebites. ${ }^{25}$ These surveys have applied the seasonal autoregressive and Bayesian time series models in their analyses. ${ }^{26},{ }^{27}$

One of the most important abiotic factors that remarkably affects the activity of animals is ambient air temperature. ${ }^{7}$ Snakes, as poikilothermic (or cold-blooded) vertebrates, are affected by temperature variations in surrounding air which limits their activity and numbers. ${ }^{11}$

The calculated correlation of snakebites with monthly averages of $\mathrm{SH}$ (in $\mathrm{h}$ ) and $\mathrm{T}$ (in ${ }^{\circ} \mathrm{C}$ ) shows a fairly strong direct relationship between snakebites, $\mathrm{SH}$, and $\mathrm{T}$, which means, an increment in monthly averages of $\mathrm{SH}$ and $\mathrm{T}$ increases the number of snakebite cases. This result is consistent with previous studies. ${ }^{28},{ }^{29}$ Snakebite also has an inverse relationship with monthly averages of $\mathrm{R}$ (in $\mathrm{mm}$ ) and $\mathrm{RH}$ (in \%). Snakebite cases and RH have a weak downhill (negative) linear relationship and despite being significant, it is not biologically very appropriate. Current results about activity of snakes with changes in $\mathrm{RH}$ were in conflict with several studies. ${ }^{28}, 30$

The percentage of snakebites was higher among males than females with a ratio of approximately $2: 1$. This issue might be linked to demographic factors, climate changes, victims' job, and active people in desired areas. Similar ratios were also found in several studies with respect to the patient's sex. ${ }^{6},{ }^{31}$ This male victims' propensity suggests a higher risk from unprotected outside activity. ${ }^{20},{ }^{25}$

Our survey indicated that about $80 \%$ of snakebites occurred in rural areas and the rest in urban areas. Several studies were consistent with these findings about region of event. ${ }^{4,6,32}$ The lack of safe houses and standard shelters, being made up of blocks, and also being close to the living place of snakes, facilitates the entry of snakes into human dwellings in most villages. Therefore, it is expected that bites occur in rural areas more than urban areas.

The current results also showed that about $80 \%$ of snakebites occurred outdoor. The results of another study in India confirms this finding. ${ }^{33}$ The Chi-square test demonstrated that location of being bitten had a significant difference with patient's sex and under both occasions males were more bitten by snakes than females. This could be due to the fact that in this area men, unlike women, spend most of their time out at work. The age group with the greatest proportion of snakebites was the 20-29 year old. Current findings on age group were exactly consistent with a study done by Pandey in Nepal. ${ }^{34}$ A study in Kashan, Iran, reported that snakebites were mostly seen in 15-24 year old. ${ }^{6}$ Many studies have generally stated that snakebites primarily occurred among 
adults. ${ }^{6,34,35}$ The high age-related incidence of snakebites amongst young people is mainly associated with their higher agricultural activities outdoors, lack of protective covers, nocturnal activity due to hot daytime climate, and dim light which expose them to a high risk of being bitten.

The greatest number of snakebites has also been related to unemployed people and farmers, followed by housewives, and students. Since nearly $80 \%$ of bites were monitored in rural areas and considering the accumulated abundant brushwood in the curtilage of rural houses, making it perfect place for snakes to hide, therefore; farm workers and housewives were more at risk to be bitten by snakes. The current results were approximately similar to some other studies which have expressed that most snakebites belonged to farm workers, who were predominantly male farmers. ${ }^{1,5,33}$

It also implies that legs and hands were the most exposed parts of the injured patients. Different studies were consistent with the present analyses about site of bite on the body. In most studies, moving parts and limbs, were at higher risk of bites compared with other parts of the body. ${ }^{6,20,33}$ The reason is that many people may not use suitable equipment such as gloves and boots in the farmlands and gardens when they are walking or working along the workplaces.

The pre-treatment interval is a time period that precedes the treatment (i.e. the elapsed time between the bite and the treatment of patients by injecting anti-venom) was less than $3 \mathrm{~h}$ in most cases (75\%). Findings from a study in the State of Piaui, north-east Brazil, showed that almost $51 \%$ of the snakebites had been brought to the infirmary in less than $3 \mathrm{~h} .{ }^{31}$ Nonetheless, in this study, only $12 \%$ of the victims received clinical attention $6 \mathrm{~h}$ after being bitten by snakes; showing that these people had low awareness about the benefits of immediate referral to the health centers after being bitten and also non-optimal access to health centers in that area.

The current results also revealed that most cases were bitten by snakes from midnight to 6 a.m.. Since most people are asleep during this time, and especially, lack of existence of safe houses and also lack of visibility in the dark villages, most of the bites happened in this time interval. These findings were in contrast to other studies. ${ }^{33,36,37}$ In a study in Tamil Nadu, India, it was observed that the least frequency of snakebites occurred from midnight to 6 a.m., whilst most biting occurred during 6-12 am. ${ }^{33}$ Therefore, high precaution should be undertaken from midnight to 6 a.m. by hospital emergency care units regarding snakebite victims.

Our findings exhibited that the incidence of bites reached its peak and trough in summer and winter, respectively. These results are in accordance with several studies suggesting that most snakebites happen during hot summer months. ${ }^{1},{ }^{5},{ }^{6}$ As seen in Fig. 2, there is generally an upward incremental trend of snakebite cases to a peak in June or July and then a gradual decrease to the end of December. These differences are likely to be due to changes in geographical conditions, temperature, and climate. Several reasons are behind this phenomenon. In fact, since snakes are cold-blooded animals; thus, they are more active in warm months; and it is supposed that these months are the times of reproduction for them. ${ }^{11}$ Many snakes may also enter living places, during warm months, to catch prey causing an increase in the activity of snakes. $^{11}$

The obtained results indicated that the victims had both local and systemic symptoms. The local symptoms were local pain and redness around the bite area due to the effects of fangs of snakes which are similar to the data of several other studies. ${ }^{5},{ }^{38}$

Current research was often confined by the inaccessibility of some clinical and lab data including blood and urine analysis due to the design of the study. Additional antecedents must be taken into account for an in-depth insight of the under study form.

\section{Conclusions}

Snakebites must be considered more seriously among the local residents in the warmer seasons especially from April to August. Bites were more common among males, rural people, and 20-29 year-old age group. Most bites took place from midnight to 6 a.m., thus; most precautions should be undertaken in this time interval in the warm months by hospital emergency care units to provide necessary facilities for the patients. Rural households must also be trained on the need for public education plans and good health services policy.

\section{Authors' contributions}

VE designed the study, contributed with data analysis, interpretation, and wrote the original draft and the final manuscript. EH carried out the research, collated snakebite data, and wrote the original draft. MDM assisted with design, analysis and provision of final manuscript. Both MHK and BV contributed to interpretation. All authors read and approved the final draft. VE is the guarantor of the paper.

\section{Funding}

None declared.

\section{Conflict of interest}

No conflict of interest is declared by the authors.

\section{Ethical approval}

None is involved.

\section{Acknowledgment}

The authors would like to thank the members of the Haji-Abad Health Network staff, Hormozgan University of Medical Sciences (HUMS), Iran, for their cooperation, assistance and patience during data collection. This research did not receive any specific grant from funding agencies in the public, commercial, or not-for-profit sectors.

\section{References}

1. Dehghani R, Mehrpour O, Shahi MP, et al. Epidemiology of venomous and semivenomous snakebites (Ophidia: Viperidae, Colubridae) in the Kashan city of the Isfahan province in Central Iran. J Res Med Sci. 2014;19(1):33.

2. Farzanpey R. Ophiology. 1990

3. Kasturiratne A, Wickremasinghe AR, de Silva N, et al. The global burden of snakebite: a literature analysis and modelling based on regional estimates of envenoming and deaths. PLoS Med. 2008;5(11):e218.

4. Feitosa ES, Sampaio V, Sachett J, et al. Snakebites as a largely neglected problem in the Brazilian Amazon: highlights of the epidemiological trends in the State of Amazonas. Revista da Sociedade Brasileira de Medicina Tropical. 2015;48:34-41.

5. Eslamian L, Mobaiyen H, Bayat-Makoo Z, Piri R, Benisi R, Naghavi-Behzad M. Snake bite in Northwest Iran: a retrospective study. J Anal Res Clin Med. 2016;4(3):133-138.

6. Dehghani R, Rabani D, Shahi MP, Jazayeri M, Bidgoli MS. Incidence of snake bites in kashan, iran during an eight year period (2004-2011). Arch Trauma Res. 2012;1(2):67.

7. Gutiérrez JM, Theakston RDG, Warrell DA. Confronting the neglected problem of snake bite envenoming: the need for a global partnership. PLoS Med. 2006;3(6):e150

8. Fox S, Rathuwithana A, Kasturiratne A, Lalloo D, De Silva H. Underestimation of snakebite mortality by hospital statistics in the monaragala District of Sri Lanka. Trans R Soc Trop Med Hyg. 2006;100(7):693-695.

9. Leong PK, Tan CH, Sim SM, et al. Cross neutralization of common Southeast Asian viperid venoms by a Thai polyvalent snake antivenom (hemato polyvalent snake antivenom). Acta tropica. 2014:132:7-14.

10. Kakanj M, Ghazi-Khansari M, Mirakabadi AZ, Daraei B, Vatanpour H. Cytotoxic effect of Iranian Vipera lebetina snake venom on HUVEC cells. Iran J Pharm Res. 2015;14(Suppl):109.

11. Latifi M, Leviton AE, Sajadian S, Zug GR. The snakes of Iran. Society for the Study of Amphibians and Reptiles; 1991.

12. Ebrahimi V, Hamdami E, Moemenbellah-Fard MD, Jahromi SE. Predictive determinants of scorpion stings in a tropical zone of south Iran: use of mixed seasonal autoregressive moving average model. $J$ Venom Anim Tox Includ Trop Dis. 2017;23(1):39

13. Zargan J, Tirgari S, Tahernejad K, Lotfi H, Farahmandzad A. Study of scorpion fauna in abomosa, great \& small Tonbs and Hengam Islands of the Persian Gulf. ISMJ. 
2003;6(1):20-24

14. Brockwell PJ, Davis RA. Introduction to time series and forecasting. Springer; 2016.

15. Shumway RH, Stoffer DS. Time series analysis and its applications. Stud Inform Control. 2000;9(4):375-376.

16. Ljung GM, Box GE. On a measure of lack of fit in time series models. Biometrika. 1978;65(2):297-303.

17. Wei WW. Time series analysis: univariate and multivariate methods. Pearson Addison Wesley; 2006.

18. Cohen J, Cohen P, West SG, Aiken LS. Applied multiple regression/correlation analysis for the behavioral sciences. Routledge; 2013.

19. Zou KH, Tuncali K, Silverman SG. Correlation and simple linear regression. Radiology. 2003;227(3):617-628

20. Dehghani R, Fathi B, Shahi MP, Jazayeri M. Ten years of snakebites in Iran. Toxicon. 2014;90:291-298.

21. Azizi K, Abedi F, Moemenbellah-Fard MD. Identification and frequency distribution of Leishmania (L.) major infections in sand flies from a new endemic ZCL focus in southeast Iran. Parasitol Res. 2012;111(4):1821-1826.

22. Farhadpour F, Telmadarraiy Z, Chinikar S, et al. Molecular detection of CrimeanCongo haemorrhagic fever virus in ticks collected from infested livestock populations in a New Endemic Area, South of Iran. Trop Med Int Health. 2016;21(3):340-347.

23. Neghab M, Moosavi S, Moemenbellah-Fard M. Prevalence of intestinal parasitic in fections among catering staff of students canteens at Shiraz, southern Iran. Pak J Biol Sci. 2006;9(14):2699-2703.

24. Hassanzadeh J, Mohammadbeigi A, Eshrati B, Moemenbellah-Fard MJ. Estimation of the regional burden of non-communicable diseases due to obesity and overweight in Markazi province, Iran, 2006-2007. J Cardiovasc Dis Res. 2012;3(1):26-31.

25. Farzaneh E, Fouladi N, Shafaee Y, Mirzamohammadi Z, Naslseraji F, Mehrpour O. Epidemiological study of snakebites in Ardabil Province (Iran). Electron Phys. 2017;9(3):3986.

26. Aragon DC, JAMd Queiroz, Martinez EZ. Incidence of snakebites from 2007 to 2014 in the State of São Paulo, Southeast Brazil, using a Bayesian time series model.
Revista da Sociedade Brasileira de Medicina Tropical. 2016;49(4):515-519.

27. Chaves LF, Chuang T-W, Sasa M, Gutiérrez JM. Snakebites are associated with poverty, weather fluctuations, and El Niño. Sci Adv. 2015;1(8):e1500249.

28. Daltry JC, Ross T, Thorpe RS, Wüster W. Evidence that humidity influences snake activity patterns: a field study of the Malayan pit viper Calloselasma rhodostoma. Ecography. 1998;21(1):25-34.

29. Paudel K, Sharma S. Study of clinico-epidemiological profile and outcome of poisonous snake bites in children. J Nepal Paediatr Soc. 2012;32(1):47-52.

30. Rocha CFD, Bergallo HG, y Conde V, Fabiane C, Bittencourt EB, HdC Santos. Richness, abundance, and mass in snake assemblages from two Atlantic Rainforest sites (Ilha do Cardoso, São Paulo) with differences in environmental productivity. Biota Neotrop. 2008;8(3).

31. NdR Oliveira, ACdR Sousa, Belmino JFB, SdS Furtado, Leite Rd S. The epidemiology of envenomation via snakebite in the State of Piauí, Northeastern Brazil. Revista da Sociedade Brasileira de Med Trop. 2015;48(1):99-104.

32. Habib A. Tetanus complicating snakebite in northern Nigeria: clinical presentation and public health implications. Acta Trop. 2003;85(1):87-91.

33. Vaiyapuri S, Vaiyapuri R, Ashokan R, et al. Snakebite and its socio-economic impact on the rural population of Tamil Nadu, India. PloS One. 2013;8(11):e80090.

34. Pandey D. Epidemiology of snake bites based on hospital survey in Chitwan and Nawalparasi district, Nepal. J Nepal Health Res Council. 2008.

35. Dadpour B, Shafahi A, Monzavi SM, Zavar A, Afshari R, Khoshdel AR. Snakebite prognostic factors: leading factors of weak therapeutic response following snakebite envenomation. Asia Pac J Med Toxicol. 2012;1(1):27-33.

36. Da Silva C, Jorge M, Ribeiro L. Epidemiology of snakebite in a central region of Brazil. Toxicon. 2003;41(2):251-255.

37. Ribeiro L, Puorto G, Jorge M. Bites by the colubrid snake Philodryas olfersii: a clinical and epidemiological study of 43 cases. Toxicon. 1999;37(6):943-948.

38. RdS Leite, Targino ITG, Lopes YACF, Barros RM, Vieira AA. Epidemiology of snakebite accidents in the municipalities of the state of Paraíba, Brazil. Ciencia saude coletiva. 2013;18(5):1463-1471. 